\title{
Distinct Roles of Synapsin I and Synapsin II during Neuronal Development
}

\section{Adriana Ferreira, ${ }^{1,2}$ Lih-Shen Chin, ${ }^{3}$ Lian $\mathrm{Li}^{3}{ }^{3}$ Lorene M. Lanier, ${ }^{3}$ Kenneth S. Kosik, ${ }^{2}$ and Paul Greengard ${ }^{3}$}

${ }^{1}$ Department of Cell and Molecular Biology and Institute for Neuroscience, Northwestern University, Chicago, Illinois, U.S.A.

${ }^{2}$ Center for Neurologic Diseases, Brigham and Women's Hospital, and Harvard Medical School, Boston, Massachusetts, U.S.A.

${ }^{3}$ Laboratory of Molecular and Cellular Neuroscience, The Rockefeller University, New York, New York, U.S.A.

Communicated by P. Greengard. Accepted November 21, 1997.

\begin{abstract}
The synapsins are a family of neuron-specific proteins, associated with the cytoplasmic surface of synaptic vesicles, which have been shown to regulate neurotransmitter release in mature synapses and to accelerate development of the nervous system. Using neuronal cultures from mice lacking synapsin I, synapsin II, or both synapsins I and II, we have now found that synapsin I and synapsin II play distinct roles in neuronal development.
\end{abstract}

Deletion of synapsin II, but not synapsin I, greatly retarded axon formation. Conversely, deletion of synapsin I, but not synapsin II, greatly retarded synapse formation. Remarkably, the deletion of both synapsins led to partial restoration of the wild phenotype. The results suggest that the synapsins play separate but coordinated developmental roles.

\section{Introduction}

The synapsins represent $1 \%$ of total neuronal protein. There are two synapsin genes, synapsin I and synapsin II, each of which can be alternatively spliced to produce a total of four synapsin isoforms (1). The synapsins appear to play a key role in the structural and functional organization of the presynaptic terminal (2). They have been implicated in controlling neurotransmitter release by clustering synaptic vesicles in a reserve pool at the nerve terminal (reviewed in ref. 2). Support for this idea was recently obtained in studies demonstrating a loss of synaptic vesicle clusters, and a concomitant reduction in trans-

Address correspondence and reprint requests to: Dr. Adriana Ferreira, Northwestern Institute for Neuroscience, Searle Building Room 5-474, 320 East Superior Street, Chicago, IL 60611, U.S.A. Phone: (312) 503-0597; Fax: (312) 503-7345; E-mail: a-ferreira@nwu.edu mitter release, from what appeared to be a reserve pool of vesicles, after microinjecting synapsin antibodies into lamprey giant neurons (3). In addition, fewer synaptic vesicles were detected in the reserve pool in synaptic terminals of synapsin I knockout mice when compared with those in wild-type ones (4-6). The synapsins also appear to play a role in the formation and maintenance of synapses. The injection of either synapsin I or synapsin II into Xenopus blastomeres accelerated synapse formation (7-9) and the transfection of synapsin II into neuroblastoma/glioma hybrid cells promoted neurite outgrowth and the differentiation of the nerve terminal (10). Conversely, depletion of either synapsin I or synapsin II resulted in inhibition of synaptogenesis in hippocampal neurons (11-13). Furthermore, the suppression of synapsin II after synapses were formed resulted in the loss of most 
of the synaptic contacts (12). These earlier studies suggested that synapsins I and II play qualitatively similar roles in regulating clustering of synaptic vesicles, neurotransmitter release, and synapse formation.

The aim of the present study was to determine whether the synapsins play distinct roles during neuronal development. Using cultures prepared from mice with targeted disruptions of the synapsin genes $(11,14)$, we demonstrate that synapsins I and II in fact play distinct roles in axonogenesis and synaptogenesis.

\section{Experimental Methods}

Generation of Synapsin-Deficient Mice

Synapsin I-, synapsin II-, and synapsin I/II-deficient mice were generated by homologous recombination $(11,14)$. Littermates of wild-type and homozygous synapsin mutant mice were used to prepare hippocampal cultures. The brain size of wild-type and mutant embryos was assessed by determining the brain wet weight at different stages of embryonic development.

\section{Preparation of Hippocampal Cultures}

Neuronal cultures were prepared from the hippocampi of embryonic day 16 (E16) mice as previously described $(11,15)$. Briefly, embryos were removed and their hippocampi dissected and freed of meninges. The cells were dissociated by trypsinization $\left(0.25 \%\right.$ for $15 \mathrm{~min}$ at $\left.37^{\circ} \mathrm{C}\right)$ followed by trituration with a fire-polished Pasteur pipette and plated onto poly-L-lysine coated coverslips (100,000 cells/60 mm dish) in MEM with $10 \%$ horse serum. After $4 \mathrm{hr}$ the coverslips were transferred to dishes containing an astroglial monolayer and maintained in MEM containing N2 supplements (16) plus ovalbumin $(0.1 \%)$ and sodium pyruvate $(0.1 \mathrm{mM})$.

\section{Immunocytochemical Procedures}

Cultures were fixed for 20 min with $4 \%$ paraformaldehyde- $0.12 \mathrm{M}$ sucrose in phosphate-buffered saline (PBS). They were then permeabilized in $0.3 \%$ triton in PBS for 5 min and rinsed twice in PBS. The cells were preincubated in $10 \%$ BSA in PBS for $1 \mathrm{hr}$ at $37^{\circ} \mathrm{C}$ and exposed to the primary antibodies (diluted in $1 \%$ BSA in PBS) overnight at $4^{\circ} \mathrm{C}$. Finally, the cultures were rinsed in PBS and incubated with secondary antibodies for $1 \mathrm{hr}$ at $37^{\circ} \mathrm{C}$. The following antibod- ies were used: anti $\alpha$-tubulin (clone DMlA); polyclonal anti-tubulin (Sigma, St. Louis, MO); anti-synaptophysin (clone SY38, Boehringer Mannheim, Indianapolis, IN.); anti mouse IgG fluorescein-conjugated; and anti-rabbit IgG rhodamine-conjugated (Boehringer Mannheim). In some experiments, rhodamine-labeled phalloidin (Molecular Probes, Eugene, OR) was included with the secondary antibody to visualize filamentous actin.

\section{Results and Discussion}

A significant difference in brain size was detected in synapsin II-deficient mice, relative to wildtype mice. At embryonic day 16 (E16), the average brain weight of synapsin II-deficient mice $(29.7 \pm 1.6 \mathrm{mg}$; mean \pm SEM$)$ was significantly lower $(\sim 17 \%)$ than that of wild-type mice $(35.5 \pm 1.7 \mathrm{mg}$; mean $\pm \mathrm{SEM} ; P<0.05)$. This decrease in brain weight in the mutant mice was reduced to $12 \%$ at E19. No difference was detected in the brain weights of synapsin I knockout or synapsin I/II double knockout mice compared with wild-type embryos (data not shown). When plated in low density culture, wild-type E16 hippocampal neurons undergo a series of morphological changes that include the formation of lamellipodial veils surrounding the cell bodies (stage I; l $\mathrm{hr}$ after plating), followed by the consolidation of the lamellipodia into shafts of short undifferentiated neurites (stage II, 4-6 $\mathrm{hr}$ after plating), and later the differentiation of one of these processes into an axon (stage III, 24 $\mathrm{hr}$ after plating) $(11,17)$. In synapsin II-deficient neurons, this timed sequence of developmental changes was altered dramatically and the morphology of the neurons was abnormal. After 1 day in culture, the majority of the wild-type neurons were at stage III (Fig. 1A, B; Table 1). In contrast, the majority of the synapsin II-deficient neurons remained at stage II (Fig. IE, F; Table 1), their neurites appeared broad and flattened, and the distribution of actin filaments was aberrant (Fig. 1E, F). In wild-type neurons, actin filaments were most prominent at the tips of developing processes; however, in the synapsin II mutants, actin filaments completely surrounded the cell bodies in stage I and the developing processes in stage II. A similarly abnormal distribution of actin filaments was observed when synapsin II expression was acutely suppressed using antisense oligonucleotides (18). In contrast, deletion of synapsin I did not affect the 

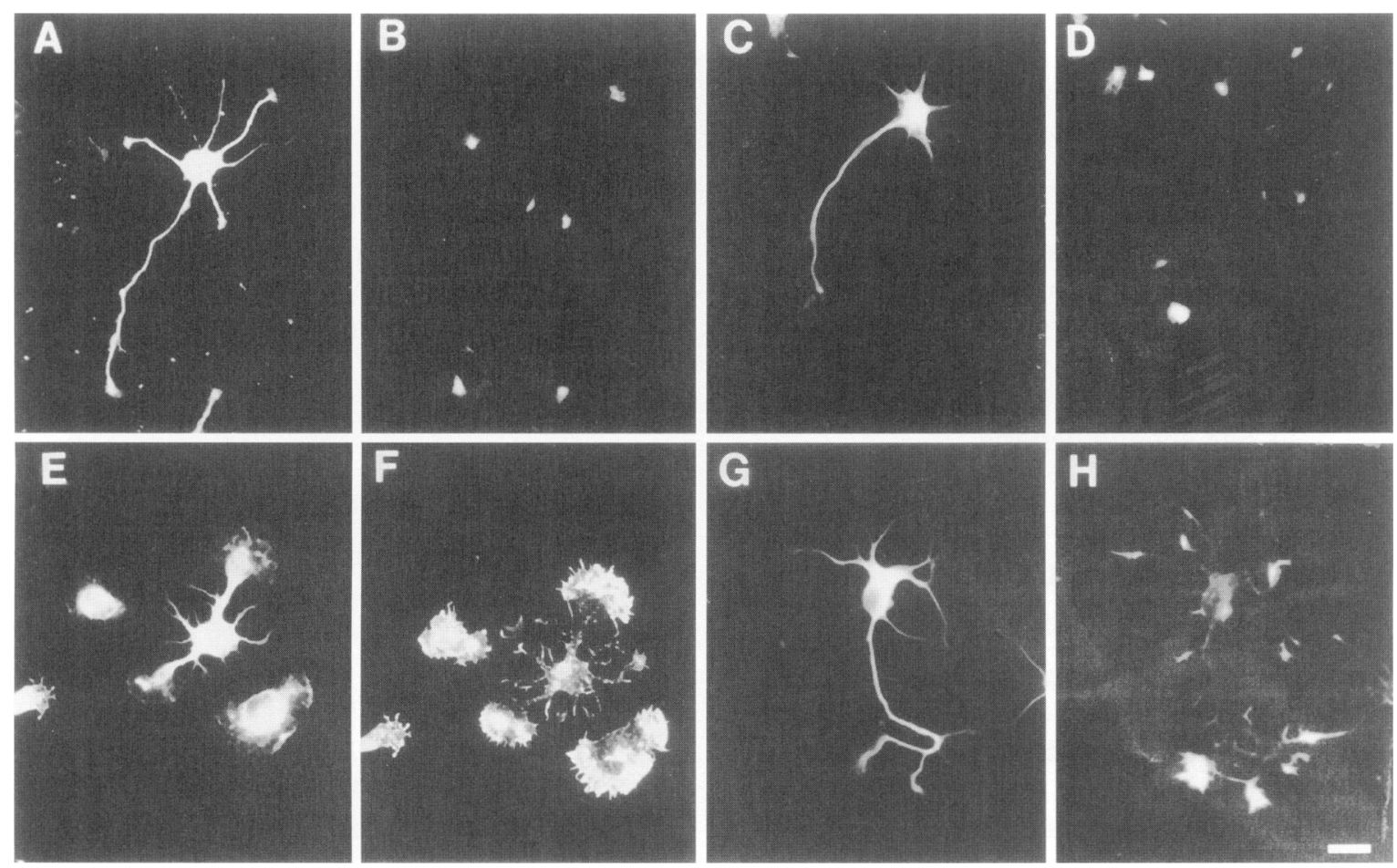

Fig. 1. Phenotype of hippocampal neurons from wild-type mice, and from synapsin I, synapsin II, and synapsin I/II double knockout mice. Hippocampal neurons obtained from embryonic E16 wild-type (A, B), synapsin I (C, D), synap$\sin$ II $(E, F)$, and synapsin I/II double $(G, H)$ knock-

timing of neurite formation or axon differentiation (stages II and III, respectively; Fig. 1C, D, Table 1), but it did affect subsequent development; axons from synapsin I-deficient neurons elongated at a slower rate and were shorter and less branched than their wild-type counterparts (11). Moreover, in the synapsin I-deficient neurons, the distribution of actin filaments (Fig. 1D) out mice were cultured for $24 \mathrm{hr}$, stained with a monoclonal antibody against tubulin (A, C, E, G) and counterstained with rhodamine-tagged phalloi$\operatorname{din}(\mathrm{B}, \mathrm{D}, \mathrm{F}, \mathrm{H})$. Note the aberrant morphology of the synapsin II-deficient neurons. Scale bar: $20 \mu \mathrm{m}$.

was normal. Remarkably, when both synapsins were deleted, the wild-type phenotype was largely restored; hippocampal neurons from synapsin I/II double knockout mice developed with the same time course as did wild-type neurons (Table 1) and the distribution of actin appeared much more normal than in the synapsin II knockout neurons (Fig. 1G, H).

Table 1. Quantitative analysis of cell morphology in wild-type and in synapsin I, synapsin II, and synapsin I/II double knockout (k.o.) mice

\begin{tabular}{lccrr}
\hline $\begin{array}{l}\text { Neuronal development } \\
\text { (stage) }\end{array}$ & Wild-type & $\begin{array}{c}\text { Synapsin I } \\
\text { k.o. }\end{array}$ & $\begin{array}{c}\text { Synapsin II } \\
\text { k.o. }\end{array}$ & $\begin{array}{c}\text { Synapsin I/II } \\
\text { k.o. }\end{array}$ \\
\hline I & $3 \pm 1$ & $4 \pm 1$ & $7 \pm 1^{*}$ & $3 \pm 1$ \\
II & $30 \pm 2$ & $32 \pm 2$ & $85 \pm 6^{*}$ & $37 \pm 3$ \\
III & $67 \pm 4$ & $64 \pm 5$ & $8 \pm 1^{*}$ & $60 \pm 4$ \\
\hline
\end{tabular}

Embryonic El6 hippocampal cultures were prepared as described $(11,17)$. Twenty-four hr after plating, cells were fixed and stained with a tubulin antibody and their morphology analyzed in 20 fields from three different experiments.

Values are given as percent of total. Each number represents the mean \pm SEM. ${ }^{\star}$ Differs from wild-type $P<0.001$. 

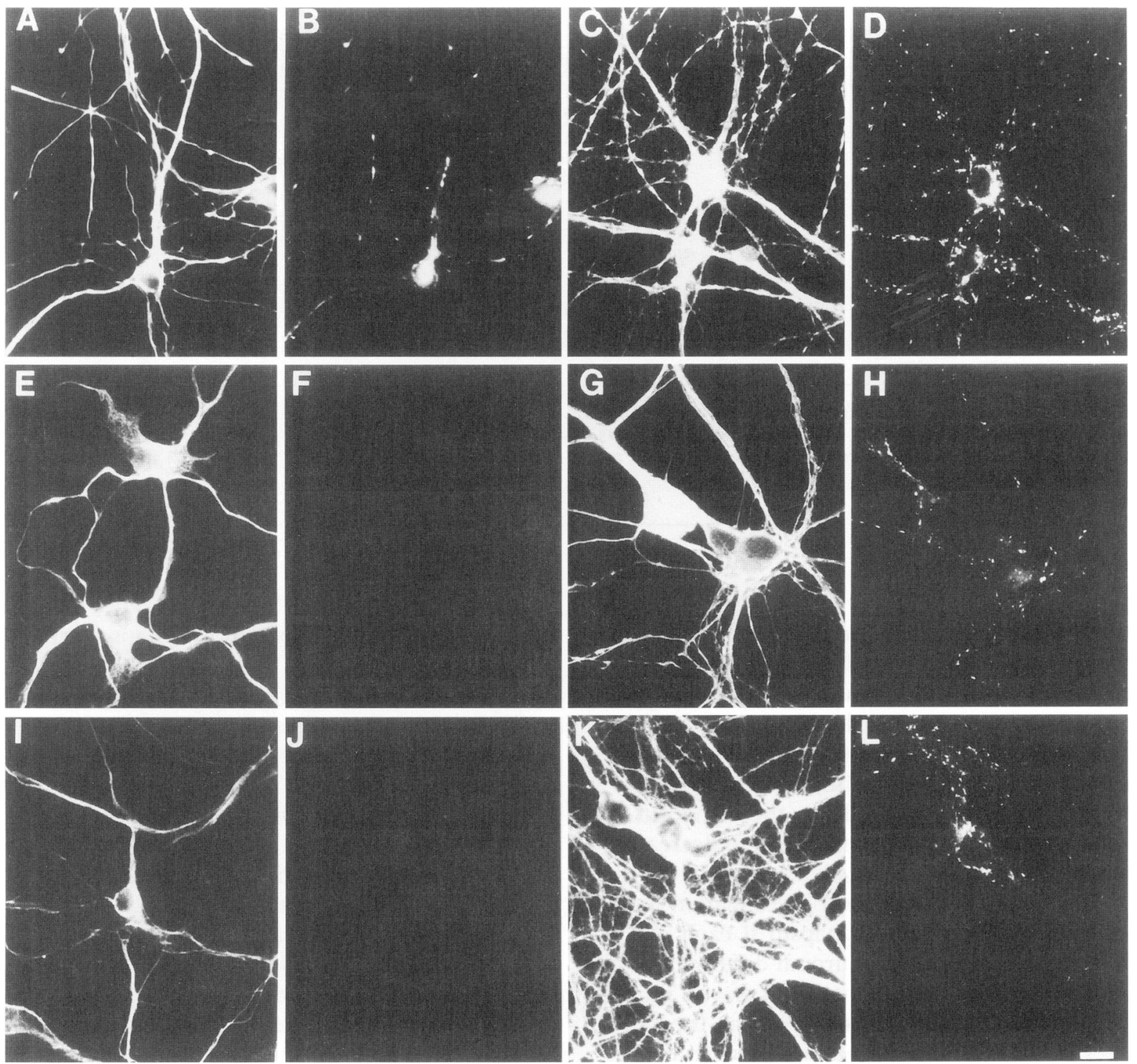

Fig. 2. Immunocytochemical detection of synapses in hippocampal neurons from wild-type mice and from synapsin II and synapsin I/II double knockout mice. Hippocampal neurons obtained from wild-type (A-D), synapsin II (E-H), and synapsin I/II double knockout (I-L) mice were fixed after 4 (A, B, E, F, I, J) or 7 (C, D, G, H, K, L) days

The effect of synapsin deletion on synaptogenesis was examined using synaptophysin, an integral protein of synaptic vesicles, as a synaptic marker $(12,19)$. Synaptophysin immunoreactive spots could be detected in cultured wild-type hippocampal neurons as early as 4 days after plating (Fig. 2; Table 2). In synapsin II-deficient neurons, synapses were first detected at 7 days in culture (Fig. 2G, H); in these neurons, synapse formation was delayed by $2-3$ days (Table 2 ).

in culture. The cells were double stained with antibodies against tubulin (A, C, E, G, I, K) and synaptophysin $(B, D, F, H, J, L)$. Note the absence of synaptophysin immunoreactive spots at 4 days in neurons from synapsin II and synapsin I/II double knockout mice. Scale bar: $20 \mu \mathrm{m}$.

These results are in agreement with previous experiments that suggested that synapsin II is involved in synapse formation and stabilization (12). Deletion of synapsin I resulted in a greater delay in synapse formation than that observed in synapsin II-deficient neurons (Table 2). Strikingly, when both synapsins were deleted, synapse formation occurred at the same rate as was observed with the synapsin II-deficient neurons and at a much greater rate than observed with 
Table 2. Synapse formation in wild-type, synapsin I, synapsin II, and synapsin I/II double knockout (k.o.) mice

\begin{tabular}{lcccc}
\hline & \multicolumn{2}{c}{ Number of synapses/cell } \\
\cline { 2 - 5 } $\begin{array}{l}\text { Days in } \\
\text { culture }\end{array}$ & Wild-type & $\begin{array}{c}\text { Synapsin I } \\
\text { k.o. }\end{array}$ & $\begin{array}{c}\text { Synapsin II } \\
\text { k.o. }\end{array}$ & $\begin{array}{c}\text { Synapsins I/II } \\
\text { k.o. }\end{array}$ \\
\hline 4 & $18.4 \pm 2$ & $0 * *$ & $0 * *$ & $0 *$ \\
7 & $40.8 \pm 3.9$ & $0.5 \pm 0.2^{* *}$ & $29.9 \pm 4.6^{*}$ & $31.1 \pm 2.62^{*}$ \\
10 & $64.2 \pm 3.9$ & $37.5 \pm 4.9 * *$ & $57.6 \pm 2.58^{*}$ & $63.8 \pm 5.8$ \\
14 & $75.5 \pm 6.5$ & $70.6 \pm 6.0$ & $73.2 \pm 4.8$ & $77.5 \pm 6.2$ \\
\hline
\end{tabular}

Embryonic E16 hippocampal neurons were grown in culture for up to 14 days. Twenty fields were analyzed for each time point and experimental condition from three different experiments. Values are given as number of synapses/cell. Each number represents the mean \pm SEM. Differs from wild type: ${ }^{*} P<0.05$ and ${ }^{* *} P<0.001$.

${ }^{a}$ Data from Chin et al., 1995 (11).

the synapsin I-deficient neurons. The levels of synaptophysin are reduced to a comparable extent in synapsin I knockout mice $(17 \%$ reduction) and in synapsin I/II double knockout mice ( $19 \%$ reduction), relative to wild-type controls (5). Therefore, the greater impairment in synaptic development observed in the synapsin I knockout mice cannot be attributed to decreased synaptophysin immunoreactivity per se.

The results of the present investigation indicate that synapsin I and synapsin II each make unique contributions to neuronal differentiation and synapse formation. Synapsin II plays a much more prominent role than synapsin I in the early stages of lamellipodial formation, neurite formation, and axon differentiation (Tables 1 and 3). Conversely, synapsin I plays a much more prom- inent role than synapsin II in synapse formation (Tables 2 and 3).

In the synapsin II-deficient neurons, the delay in the early stages of development (Table 1) can account at least in part for the delay in synapse formation (Table 2). However, treatment of cultured wild-type hippocampal neurons with synapsin II antisense oligonucleotides causes a reversible disappearance of synapses, indicating that synapsin II may also be involved in synapse formation and/or stabilization (12). In the synapsin I-deficient neurons, the delay in synaptogenesis cannot be accounted for by an effect on axonal differentiation and/or elongation. Two lines of evidence support this view. First, in the present study, we demonstrated that although synapsin II-deficient neurons failed to

Table 3. Comparison of the phenotype of developing neurons from synapsin I, synapsin II, and synapsin I/II knockout (k.o.) mice

\begin{tabular}{lllc}
\hline & $\begin{array}{c}\text { Synapsin I } \\
\text { k.o. }\end{array}$ & $\begin{array}{c}\text { Synapsin II } \\
\text { k.o. }\end{array}$ & $\begin{array}{c}\text { Synapsin I/II } \\
\text { k.o. }\end{array}$ \\
\hline Lamellipodia formation & Normal & Impaired & Normal \\
Neurite formation & Normal & Impaired & Normal \\
Axon differentiation & Normal & Impaired & Normal \\
Synapse formation & Impaired & Impaired $^{a}$ & Impaired $^{a}$ \\
Cytoskeletal organization & Normal & Impaired $^{\text {Intermediate }}$
\end{tabular}

${ }^{a} \mathrm{~A} 2$ - to 3-day delay in synapse formation could be attributable, in part, to a corresponding delay in axon formation. 
elongate their axons for more than $48 \mathrm{hr}$, they formed synapses earlier than the synapsin I mutant neurons, which differentiated axons with the same time course as did their wild-type counterparts (Table 1-3). Second, synapsin Ideficient neurons are delayed in their ability to form synapses even after making contact with other cells (13).

It is of particular interest that the synapsin I/II double deletion largely eliminated the deleterious effects both of the synapsin II deletion on the early stages of neuronal differentiation and of the synapsin I deletion on synapse formation (Tables 1-3). If, as suggested (5), the synapsins have redundant functions, one might expect to observe more severe developmental defects in the double knockout than in either single knockout. On the contrary, our data indicate that the developmental defects were less severe in the double knockout than in either single knockout.

During normal neuronal development, the protrusive activity of actin filaments drives the formation of lamellipodial structures; process formation and directional elongation require that this protrusive activity be suppressed along the axon shaft. It has been proposed that this suppression is mediated by unidentified proteins that are capable of cross-linking microtubules and actin filaments (20). There is now substantial evidence that synapsin I, and even more potently, synapsin II, nucleates actin polymerization and bundles actin filaments (21). Moreover, synapsin I binds and bundles microtubules through a domain with high homology to synapsin II $(22,23)$. Our data suggest that, as a consequence of the loss of synapsin II, actin protrusive activity may remain unsuppressed, resulting in the formation of actin veils that surround the neuritic processes. It will be of interest to determine the extent to which the distinct effects of synapsin I and synapsin II on neuronal development are attributable to differences in their ability to organize the cytoskeleton.

\section{Acknowledgments}

This work was supported by NIH grant MH39327 (P.G.) and by Northwestern University grant 100510330 U (A.F.).

\section{References}

1. Sudhof TC, Czernik AJ, Kao H, Takei K, Johnston PA, Horiuchi A, Wagner M, Kanazir SD, Perin MS,
De Camilli P, Greengard P. (1989) Synapsins: Mosaic of shared and individual domains in a family of synaptic vesicle phosphoproteins. Science 245: 1474-1480.

2. Greengard P, Valtorta F, Czernik AJ, Benfenati F. (1993) Synaptic vesicle phosphoproteins and regulation of synaptic function. Science 259: 780-785.

3. Pieribone VA, Shupliakov O, Brodin L, HilfikerRothenfluh S, Czernik AJ, Greengard P. (1995) Distinct pools of synaptic vesicles in neurotransmitter release. Nature 375: 493-497.

4. Li L, Chin L, Shupliakov O, Brodin L, Sihra T, Hvalby $\emptyset$, Jensen V, Zieng D, McNamara JO, Greengard P, Andersen P. (1995) Impairment of synaptic vesicle clustering and of synaptic transmission, and increased seizure propensity, in synapsin I-deficient mice. Proc. Natl. Acad. Sci. U.S.A. 92: 9235-9239.

5. Rosahl TW, Spillane D, Missler M, Herz J, Selig D, Wolff JR, Hammer RE, Malenka RC, Südhof TC. (1995) Essential functions of synapsin I and II in synaptic vesicle regulation. Nature 375: 488-493.

6. Takei $Y$, Harada A, Takeda S, Kobayashi K, Terada S, Noda T, Takahashi T, Hirokawa N. (1995) Synapsin I deficiency results in the structural change in the presynaptic terminals in the murine nervous system. J. Cell Biol. 131: 1789-1800.

7. Lu B, Greengard P, Poo MM. (1992) Exogenous synapsin I promotes functional maturation of developing neuromuscular synapses. Neuron 8: 521529.

8. Schaeffer E, Alder J, Greengard P, Poo MM. (1994) Exogenous synapsin I promotes functional maturation of developing neuromuscular synapses. Proc. Natl. Acad. Sci. U.S.A. 91: 3882-3886.

9. Valtorta F, Iezzi N, Benfenati F, Lu B, Poo M-M, Greengard P. (1995) Accelerated structural maturation induced by synapsin $I$ at developing neuromuscular synapses of Xenopus Iaevis. Eur. J. Neurosci. 7: 261-270.

10. Han HQ, Nichols RA, Rubin MR, Bahler $M$, Greengard P. (1991) Induction of formation of presynaptic terminals in neuroblastoma cells by synapsin IIb. Nature 349: 697-700.

11. Chin LS, Li L, Ferreira A, Kosik KS, Greengard P. (1995) Impairment of axonal development and of synaptogenesis in hippocampal neurons of synapsin I-deficient mice. Proc. Natl. Acad. Sci. U.S.A. 92: 9230-9234.

12. Ferreira A, Han HQ, Greengard $P$, Kosik KS. (1995) Suppression of synapsin II inhibits the formation and maintenance of synapses in hippocampal culture. Proc. Natl. Acad. Sci. U.S.A. 92: 9225-9229.

13. Ferreira A, Li L, Chin LS, Greengard P, Kosik KS. (1996) Postsynaptic element contributes to the delay in synaptogenesis in synapsin I deficient neurons. Mol. Cell. Neurosci. 8: 286-299.

14. Shupliakov O, Magarinos AM, Li L, Chin LS, Gustafsson J, McEwen BS, Pieribone V, Greengard 
$\mathrm{P}$, Brodin L. Structural alterations in nerve terminals of synapsin-deficient mice. J. Cell Biol. (in press).

15. Goslin K, Banker GA. (1991) Rat hippocampal neurons in low-density culture. In: Banker GA, Goslin K (eds). Culturing nerve cells. MIT Press, Cambridge, MA, pp. 251-283.

16. Bottenstein JE, Sato GH. (1979) Growth of a rat neuroblastoma cell line in serum-free supplemented media. Proc. Natl. Acad. Sci. U.S.A. 76: 514517.

17. Dotti CG, Sullivan CA, Banker GA. (1988) The establishment of polarity by hippocampal neurons in culture. J. Neurosci. 8: 1454-1468.

18. Ferreira A, Kosik KS, Greengard P, Han HQ. (1994) Aberrant neurites and synaptic vesicle protein deficiency in synapsin II-depleted neurons. Science 264: 977-979.
19. Fletcher TP, Cameron P, De Camilli P, Banker GA. (1991) The distribution of synapsin I and synaptophysin in hippocampal neurons in culture. J. Neurosci. 11: 1617-1632.

20. Mitchison T, and Kirschner M. (1988) Cytoskeletal dynamics and nerve growth. Neuron 1: 761772.

21. Chilcote TJ, Siow YL, Schaeffer E, Greengard P, Thiel G. (1994) Synapsin IIa bundles actin filaments. J. Neurochem. 63: 1568-1571.

22. Baines AJ, Bennett V. (1986) Synapsin I is a microtubule-bundling protein. Nature 319: 145147.

23. Petrucci TC, Morrow JF. (1991) Synapsin I: an actin-bundling protein under phosphorylation control. Biochemistry 30: 413-422. 